\title{
Presenteeism among Japanese IT Employees: Personality, Temperament and Character, Job Strain and Workplace Support, and Mental Disturbance
}

\author{
Yuko Kono$^{1}$, Masayo Uji², Eisuke Matsushima ${ }^{3}$ \\ ${ }^{1}$ Liaison Institute for Counseling Inc., Tokyo, Japan \\ ${ }^{2}$ Department of Bioethics, Kumamoto University Graduate School of Life Sciences, Kumamoto, Japan \\ ${ }^{3}$ Section of Liaison Psychiatry and Palliative Medicine, Division of Comprehensive Patient Care, Graduate \\ School of Medical and Dental Sciences, Tokyo Medical and Dental University, Tokyo, Japan \\ Email: liaison21@mac.com
}

Received 26 July 2015; accepted 4 December 2015; published 7 December 2015

Copyright (C) 2015 by authors and Scientific Research Publishing Inc.

This work is licensed under the Creative Commons Attribution International License (CC BY). http://creativecommons.org/licenses/by/4.0/

(c) (i) Open Access

\begin{abstract}
To study correlates of presenteeism among Japanese IT employees, a cross-sectional study in 440 employees of four IT companies was studied with a net-based questionnaire survey. A structural regression analysis revealed that presenteeism (measured by the Work Limitation Questionnaire) was directly associated with common mental symptoms (measured by the Clinical Outcomes in Routine Evaluation-Outcome Measure) and job strain (measured by the Job Strain Questionnaire), common mental symptoms mediated the effects of job strain and poor workplace social support as well as high Harm Avoidance and low Self-directedness and Cooperativeness (measured by the Temperament and Character Inventory-Revised) upon presenteeism. IT company workers presenteeism may be a result of complicated effects of common mental symptoms, job strain and poor workplace social support, and personality traits.
\end{abstract}

Keywords

Presenteeism, Common Mental Symptoms, Job Strain, Workplace Social Support, Personality

\section{Introduction}

Health problems have a substantial impact on work productivity. Absence due to disease causes economical loss.

How to cite this paper: Kono, Y., Uji, M., \& Matsushima, E. (2015). Presenteeism among Japanese IT Employees: Personality, Temperament and Character, Job Strain and Workplace Support, and Mental Disturbance. Psychology, 6, 1971-1983.

http://dx.doi.org/10.4236/psych.2015.615195 
In addition to such direct loss due to health problems, indirect impact due to disease has increasingly been paid attention among clinicians and researchers. Productivity loss occurs when employees are still at work but impaired due to health problems. This is called presenteeism (Brown, Gilson, Burton, \& Brown, 2011; Cooper \& Dewe, 2008). Economic loss due to presenteeism was higher than medical costs in an American study (Goetzel, Long, Ozminkowski, Hawkins, Wang, \& Lynch, 2004).

Employees with depression were more likely, when followed six months, to be unemployed as well as, if still employed, have job turn over and presenteeism (Lerner, Adler, Chang, Lapitsky, Hood, Perissinotto et al., 2004). A review demonstrated that those people with depression were more likely to have unemployment, absences, and at-work performance deficits (Lerner \& Henke, 2008). A study in a large financial services corporation showed that odds ratio of work limitation due to health problems was highest among those employees with depression than those with other conditions including arthritis, back pain, diabetes, heart disease and irritable bowel (Burton, Pransky, Conti, Chen, \& Edington, 2004). It was reported that productivity loss due to depression was higher among employees with occupation requiring proficiency in decision-making and communication, or frequent customer contact (Lerner, Adler, Chang, Berndt, Irish, Lapitsky, Hood, Reed, \& Rogers, 2004).

Past investigations on impact of mental health problems on presenteeism have been on depression. While depression is an important mental health problem, other conditions such as anxiety (Anderson \& Andrews, 2006), suicidality, psychosocial functioning and psychological well-being should also be studied in terms of their association with at-work performance.

Presenteeism should also be viewed in association with job stress and workplace social support. The job demand-control model (Karasek, 1979) indicates that stress responses of workers occur when heavy workload is coupled with lack of their discretion in work. Job demand reflects the extent to which the worker's job is demanding and job control reflects the extent to which the worker has control over his or her assigned task. The job demand-control model was modified into the job demand-control-support model. Here added was a dimension of social support at workplace. This theory dictates that workers with high level of workplace social support are less likely to show stress responses even when job strain is high (De Lange, Taris, Kompier, Houtman, \& Bongers, 2003; Park, Wilson, \& Lee, 2004). However, little has been studied as to the association between presenteeism and job demand and lack of workplace social support. We hypothesized in this study that excessive job strain and lack of workplace social support would predict presenteeism directly and also directly through mediation by mental disturbance such as depression and anxiety.

Personality and mental health problems have long been excessively studied. Of many theories of mental health problems-related personality traits, Cloninger's (Cloninger, Svrakic, \& Przybeck, 1993) psychobiology model of personality has been studied by many researchers. In this model, personality consists of temperament and character. Temperament means individual differences in basic emotional responses. It has four dimensions including Harm Avoidance, Novelty Seeking, Reward Dependence, and Persistence. The dimensions of temperament are moderately heritable and stable throughout life. Character reflects an individual's life goals, value system, and self-conscious emotions. It has three dimensions including Self-directedness, Cooperativeness, and Self-transcendence. They are weakly heritable and moderately influenced by social learning. Ample evidence has accumulated that depression is characterised by high Harm Avoidance and low Self-directedness (Celikel, Kose, Cumurcu, Erkorkmaz, Sayar, Borckardt, \& Cloninger, 2009; Farmer, Mahmood, Redman, Harris, Sadler, \& McGuffin, 2003; Ghazinour, Richter, \& Eisemann, 2003; Goncalves \& Cloninger, 2010; Hansenne, Pitchot, Moreno, Machurot, \& Ansseau, 1998; Hansenne, Reggers, Pinto, Kjiri, Ajamier, \& Ansseau, 1999; Janowsky, Morter, Hong, \& Howe, 1999; Jylhä \& Isometsä, 2006; Jylhä, Mantere, Melartin, Suominenm, Vuorilehto, Arvilommi, Holma, Holma, Leppämäki et al., 2011; Kusunoki, Sato, Taga, Yoshida, Komori, Narita et al., 2000; Loftus, Garno, Jaeger, \& Malhotra, 2008; Matsudaira \& Kitamura, 2006; Minaya \& Fresán, 2009; Tanaka, Kijima, \& Kitamura, 1997; Tillman, Geller, Craney, Bolhofner, Williams, Zimerman et al., 2003). Combination of high HA and low SD is also a hallmark of other mental disorders such as panic disorder (Marchesi, De Panfilis, Cantoni, Giannelli, \& Maggini, 2008; Wachleski, Salum, Blaya, Kipper, Paludo, Salgado, \& Manfro, 2008), obsessive compulsive disorder (Alonso, Menchón, Jiménez, Segalàs, Mataix-Cols, Jaurrieta et al., 2008; Bejerot, Schlette, Ekselius, Adolfsson, \& von Knorring, 1998; Kim, Kang, \& Kim, 2009), phobic disorders (Cho, Jung, Kim, Hwang, Shin, Kim, Chungh, \& Kim, 2009; Pallanti, 2007), and post traumatic stress disorder (Ruchkin, Schwab-Stone, Koposov, Vermeiren, \& Steiner, 2002). Cooperativeness has also been reported as associated with depression (Farmer, Mahmood, Redman, Harris, Sadler, \& McGuffin, 2003; Farmer, \& Seeley, 2009; Ghazinour, Richter, \& Eisemann, 2003; Goncalves \& Cloninger, 2010; Hansenne, Reggers, Pinto, Kjiri, Ajamier, \& 
Ansseau, 1999; Kusunoki, Sato, Taga, Yoshida, Komori, Narita, Hirano, Iwata, \& Ozaki, 2000; Matsudaira \& Kitamura, 2006; Minaya \& Fresán, 2009; Sato, Narita, Hirano, Kusunoki, Sakado, \& Uehara, 2001), bipolar disorder (Engström, Brändström, Sigvardsson, Cloninger, \& Nylander, 2004; Evans, Akiskal, Keck, McElroy, Sadovnick, Remick, \& Kelsoe, 2005; Nery, Hatch, Glahn, Nicoletti, Monkul, Najt et al., 2008; Sayın, Kuruoğlu, Güeç, \& Aslan, 2007; Tillman, Geller, Craney, Bolhofner, Williams, Zimerman, Frazier, \& Beringer, 2003), panic disorder (Marchesi, De Panfilis, Cantoni, Giannelli, \& Maggini, 2008; Wachleski, Salum, Blaya, Kipper, Paludo, Salgado, \& Manfro, 2008), social phobia (Mörtberg, Bejerot, \& Wistedt, 2007), obsessive-compulsive disorder (Alonso, Menchón, Jiménez, Segalàs, Mataix-Cols, Jaurrieta et al., 2008; Bejerot, Schlette, Ekselius, Adolfsson, \& von Knorring, 1998; Kim, Kang, \& Kim, 2009; Kusunoki, Sato, Taga, Yoshida, Komori, Narita, Hirano, Iwata, \& Ozaki, 2000), post-traumatic stress disorder (Yoon, Jun, An, Kang, \& Jun, 2009), anorexia nervosa (Cassin \& von Ranson, 2005), an d bulimia nervosa (Álvarez-Moya, Jiménez-Murcia, Granero, Vallejo, Krug, Bulik, \& Fernández-Aranda, 2007).

Personality traits are also likely to be associated with perceived stain at workplace. It has been often reported that life stressors were precede by individuals' certain personality traits (Daley, Hammen, Davila, \& Burge, 1998; Farmer, Harris, Redman, Sadler, Mahmood, \& McGuffin, 2000; Farmer, Redman, Harris, Mahmood, Sadler, \& McGuffin, 2001; Finch \& Graziano, 2001; Hazel, Hammen, Brennan, \& Najman, 2008; Kendler, Karkowski, \& Prescott, 1999; Koenen, Moffitt, Poulton, Martin, \& Caspi, 2006; Maciejewski, Prigerson, \& Mazure, 2000; Middledorp, Cath, Beem, Willemsen, \& Boomsma, 2008). Quality and quantity of support from others may be determined by personality traits (Bergeman, Plomin, Pedersen, McClea, \& Nesselroade, 1990; Bolger \& Eckenrode, 1991; Finch \& Graziano, 2001; Ghazinour, Richter, \& Eisemann, 2003; Kessler, Kendler, Heath, Neale, \& Eaves, 1992; Tse \& Bond, 2003).

Considering such research on the association between high Harm Avoidance and low Self-directedness and a different variety of common mental disorders and perceptive nature of job strain and social support, we hypothesized that such personality traits would be associated with job strain and workplace social support. Hence the effects of high Harm Avoidance and low Self-directedness on mental disorders may be mediated by perceived job strain and low social support. We were also interested in whether such personality traits would directly predict presenteeism.

Our research hypotheses in this study are thus (Figure 1);

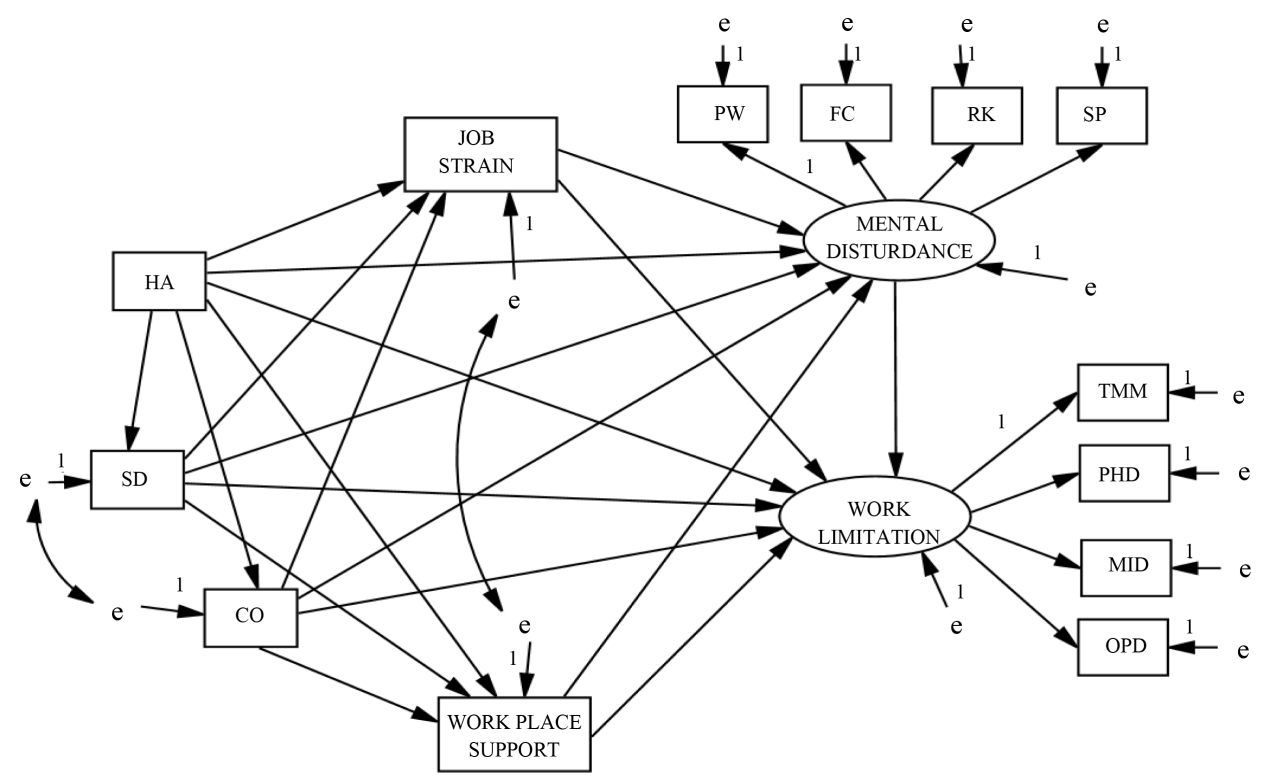

Figure 1. Original path model. TMM, WLQ time management; PHD, WLQ physical demands; MID, WLQ mental and interpersonal demands; OUD, WLQ output demands; SP, CORE-OM symptomatic problems; RK, CORE-OM Risk; FC, CORE-OM functioning; PW, CORE-OM Psychological well-being; JS, JSQ, Job STRAIN; SOCS, JSQ, workplace social support; HA, TCI Harm avoidance; NS, TCI novelty seeking; RD, TCI reward dependence; PS, TCI persistence; SD, TCI Self-directedness; CO, TCI, Cooperativeness; ST, TCI Self-transcendence. 
1) Presenteeism is predicted by job strain as well as lack of workplace social support;

2) This effect is mediated by common mental symptoms;

3) High Harm Avoidance and low Self-directedness and Cooperativeness predict presenteeism and common mental symptoms directly and;

4) The effects High Harm Avoidance and low Self-directedness and Cooperativeness on presenteeism and common mental symptoms are mediated by job strain as well as lack of workplace social support.

\section{Methods}

\subsection{Participants}

We solicited the participation in the present web-based questionnaire survey a total of 2360 employees of four information technology companies located all in Tokyo. We chose four companies based on the fact that they had different managerial and occupational backgrounds. Company A was the biggest IT company in Japan. The number of employees was about 1500. Company B was a subcontractor linked to a leading company. Company $\mathrm{C}$ was an independent company contracting mainly with government offices. Company D was specialised on Internet business. Responses were provided by 441 (19\%): 55 from company A, 110 from company B, 191 from company C, and 85 from company D. They were 370 men and 70 women. One participant did not give information about gender. Their age was between 22 and 65. Their mean (SD) age was 22.0 (10.) years. The study was conducted in July and August, 2013.

\subsection{Measures}

\subsubsection{Presenteeism}

Presenteeism was measured by the Work Limitation Questionnaire (WLQ: Lerner, Amick, Rogers, Malspeis, \& Bungay, 2001), a self-report with 25 items. It measures employee's ability to perform four specific set of job demands including Time Management (TMM: five items, e.g., difficulty working required hours), Physical Demand (PHD: six items, e.g., ability to walk to different work locations), Mental and Interpersonal Demands (MID: nine items, e.g., difficult doing work carefully) and Output Demands (OPD: five items, e.g., difficulty handling the workload). Each scale implies the percent of work time in the previous two weeks that an employee's physical and or emotional health problems interfered with his or her ability to perform each group of job demand. Item scores within each scale is averaged and transformed to a 0 (no limitation) to 100 (limited 100\% of the working time) scale. This instrument's good validity and reliability was reported by its original authors (Lerner, Amick, Lee, Rooney, Rogers, Chang, \& Berndt, 2003; Lerner, Reed, Massarotti, Wester, \& Burke, 2002). The WLQ was translated into Japanese and it showed god validity (Ida, Nakagawa, Miura, Ishikawa, \& Yakura, 2012). In the present participants, internal reliabilities expressed by Cronbach's $\alpha$ were $.83, .89, .91$, and .87 for TMM, PHD, MID, and OPD, respectively.

\subsubsection{Mental Disturbance}

Different symptoms of common mental disorders were measured by the Clinical Outcomes in Routine Evaluation-Outcome Measure (CORE-OM: Evans, Mellor-Clark, Margison, Barkham, Audin, Connell et al., 2000). This is a self-report on common psychiatric symptoms and psychosocial functioning. The CORE-OM is with 34 items. It covers four areas including Symptomatic Problems (i.e., anxiety, depression, physical symptoms, and trauma), Risk (i.e., risks to others and self), Functioning (i.e., close, general, and social functioning), and Psychological Well-being. The reliability and validity of the CORE-OM was confirmed by its original authors (Evans, Connell, Barkham, Margison, McGrath, Mellor-Clark et al., 2002). The CORE-OM was translated into Japanese and was shown excellent in its psychometric properties (Uji, Sakamoto, Adachi, \& Kitamura, 2012). In the present participants, internal reliabilities expressed by Cronbach's $\alpha$ were $.90, .84, .87$, and .69 for Symptomatic Problems, Risk, Functioning, and Psychological Well-being, respectively.

The template is used to format your paper and style the text. All margins, column widths, line spaces, and text fonts are prescribed; please do not alter them. You may note peculiarities. For example, the head margin in this template measures proportionately more than is customary. This measurement and others are deliberate, using specifications that anticipate your paper as one part of the entire journals, and not as an independent document. Please do not revise any of the current designations. 


\subsubsection{Job Strain and Workplace Support}

The job stress and workplace social support was measured by the Job Strain Questionnaire (JSQ: Steptoe, Cropley, \& Joekes, 1999). Based on Karasek’s (1979) job demand-control theory, the JSQ measures Job Demand (three items, e.g., "My job is hectic"), Job Control (three items, e.g., "I have freedom to decide what I do in my job”), and Skill Utilization (four items, e.g., "My job involves me learning new things"). (Steptoe et al, 1999) defined the Job strain Index as.

$$
\text { Job Strain Index = Job Demand/(Job Control×Skill Utlization })
$$

The JSQ also includes five items to measure Workplace Social Support for example "I have a good relationship with my supervisors". The JSQ was translated into Japanese and used in a working people population study (Takagishi, Sakata, \& Kitamura, 2011). In the present participants, internal reliabilities expressed by Cronbach's $\alpha$ were .78, .79, and .67 for Job Demand, Job Control, and Skill Utilization, respectively.

\subsubsection{Temperament and Character}

The participants' temperament and character was measured by the Temperament and Character Inventory-Revised (TCI-R: Cloninger, 1999). The TCI-R is a self-report measuring temperament and character according to Cloninger's psychobiology model of personality (Cloninger, Svrakic, \& Przybeck, 1993; Cloninger, Przybeck, Svrakic, \& Wetzel, 1994). Temperament includes Harm Avoidance, Novelty Seeking, Reward Dependence, and Persistence. Character includes Self-directedness, Cooperativeness, and Self-transcendence. The TCI-R consists of 240 items with a 5-point Likert scale. The TCI-R was translated into Japanese. In the present participants, internal reliabilities expressed by Cronbach's $\alpha$ were $.82, .58, .55, .33, .46, .50$, and .42 for Harm Avoidance, Novelty Seeking, Reward Dependence, Persistence, Self-directedness, Cooperativeness, and Self-transcendence, respectively.

\subsection{Data Analyse}

Of 441 participants, 434 (98\%) responded data without missing values. After calculating means and SDs of all the variables used in this study, we collated all of them. In a simple correlational matrix, we obtained variables that were correlated significantly with the four WLQ scale scores. We constructed a structural regression model using a structural equation modelling (SEM: Klein, 2005). In the original model (Figure 1), we posited that 1) two latent variables Work Limitation and Mental Disturbance consisted of the scale scores of the WLQ and CORE-OM, respectively, 2) Mental Disturbance predicted Work Limitation, 3) Job Strain and Workplace Social Support as well as temperament and character scale scores predicted both Mental Disturbance and Work limitation, 4) temperament and character scale scores predicted Job Strain and Workplace Social Support, and 5) temperament scale scores predicted character scale scores. The fit of each model with the data was examined in terms of chi-squared (CMIN), comparative fit index (CFI), and root mean square error of approximation (RMSEA). According to conventional criteria, a good fit would be indicated by CMIN/df $<2$, CFI $>0.97$, and RMSEA $<0.05$; an acceptable fit by CMIN/df $<3$, CFI $>0.95$, and RMSEA $<0.08$.

Then SEM models were "trimmed" by deleting the least significant path from the model one by one as far as $\chi^{2}(\mathrm{~d})$ did not reach a statistically significant level (Klein, 2005). Because of the cross-sectional nature of the research design, we examined the goodness-of-fit of alternative models.

All the statistical analyses were conducted using the Statistical Package for Social Science (SPSS) version 20.0 and Amos 20.0.

\subsection{Procedure}

The participants were asked via e-mail to participate in the net survey. Anonymity was confirmed. The participants were asked via e-mail to participate in the net survey. Each assessment took about three quarter of an hour. Anonymity was confirmed.

\section{Results}

Means and SDs of all the variables used in this study is in Table 1. The four WLQ scale scores were correlated with each other. None of the WLQ scale scores were associated with gender. Age was correlated slightly with 
Table 1. Means, SDs of all variables used in this study $(\mathrm{N}=434)$.

\begin{tabular}{|c|c|c|c|}
\hline & Mean & SD & Alpha \\
\hline WLQ Time Management & 18.4 & 17.5 & 0.83 \\
\hline WLQ Physical Demands & 35.2 & 21.3 & 0.89 \\
\hline WLQ Mental and Interpersonal Demands & 20.3 & 16.2 & 0.91 \\
\hline WLQ Output Demands & 20 & 18.2 & 0.87 \\
\hline CORE-OM Symptomatic Problems & 26.2 & 8.8 & 0.9 \\
\hline CORE-OM Risk & 8.6 & 3.4 & 0.84 \\
\hline CORE-OM Functioning & 28.6 & 7.6 & 0.87 \\
\hline CORE-OM Psychological Well-being & 10.2 & 3 & 0.69 \\
\hline JSQ, JSQ Job Strain & 7.3 & 2.6 & --- \\
\hline JSQ, Workplace Social Support & 14.1 & 2.4 & 0.67 \\
\hline TCI-R Harm Avoidance & 56.2 & 9.6 & 0.82 \\
\hline TCI-R Novelty Seeking & 52.6 & 6.5 & 0.58 \\
\hline TCI-R Reward Dependence & 55.5 & 5.8 & 0.55 \\
\hline TCI-R Persistence & 43 & 4.8 & 0.33 \\
\hline TCI-R Self-directedness & 62.6 & 9.2 & 0.76 \\
\hline TCI-R Cooperativeness & 60.7 & 5.5 & 0.5 \\
\hline TCI-R Self-transcendence & 43 & 5.2 & 0.42 \\
\hline
\end{tabular}

TMM, WLQ Time Management; PHD, WLQ Physical Demands; MID, WLQ Mental and Interpersonal Demands; OUD, WLQ Output Demands; SP, CORE-OM Symptomatic Problems; RK, CORE-OM Risk; FC, CORE-OM Functioning; PW, CORE-OM Psychological.

$\operatorname{TMM}(r=-.24, p<.001)$, MID $(r=-.23, p<.001)$, and OPD $(r=-.22, p<.001)$.

The WLQ scale scores were also correlated with almost all of the CORE-OM and JSQ subscale scores. Also they were correlated with Harm Avoidance, and low Self-directedness and Cooperativeness scores. All the CORE-OM subscales were correlated with each other. They were also correlated with high JSQ Job Satisfaction and low Workplace Social Support scores as well as with Harm Avoidance and low Self-directedness and Cooperativeness scores. JS and SOCS scores were inversely correlated with each other. High Job Satisfaction and low Workplace Social Support were correlated with low Self-directedness and Cooperativeness (Table 2).

Because only Harm Avoidance, Self-directedness and Cooperativeness were correlated with the WLQ, COREOM, and JSQ subscale scores, we constructed a SEM structural regression model. The original path model showed an acceptable fit with data: $\chi^{2} / \mathrm{df}=3.3$, CFI $=.960$, and RMSEA $=.072$ (Figure 2). In this model, Harm Avoidance predicted low Self-directedness and Cooperativeness as well as Mental Disturbance. Low Self-directedness and Cooperativeness predicted high Job Strain and poor Workplace Support whereas low Self-directedness but not Cooperativeness predicted Mental Disturbance. Job Strain and poor Workplace Support predicted Mental Disturbance whereas Job Strain but not poor Workplace Support predicted Work limitation directly.

Then we "trimmed" the model by deleting one path by another examining whether the increase of $\chi^{2}$ did not go beyond $5 \%$ significance level $(\mathrm{df}=1)$ no non-significant path could be deleted. In the final model, all the non-significant paths in the original model (Figure 1) could be successfully deleted without a significant increase of $\chi^{2}$.

In order to consider another possible model in which Work Limitation would rather predict Mental Disturbance, we added a path from Work Limitation to Mental Disturbance (Figure 3). This non-recursive model showed that it was Mental Disturbance that predicted Work Limitation but not the other way round. About 50\% of the variance of Work Limitation was explained by this non-recursive model. 
Table 2. Inter-correlations of all variables used in this study $(\mathrm{N}=434)$.

\begin{tabular}{|c|c|c|c|c|c|c|c|c|c|c|c|c|c|c|c|c|c|}
\hline & 1 & 2 & 3 & 4 & 5 & 6 & 7 & 8 & 9 & 10 & 11 & 12 & 13 & 14 & 15 & 16 & 17 \\
\hline $1 \mathrm{TMM}$ & --- & & & & & & & & & & & & & & & & \\
\hline 2 PHD & $.24^{* * *}$ & --- & & & & & & & & & & & & & & & \\
\hline 3 MID & $.72^{* * * *}$ & $.29^{* * *}$ & --- & & & & & & & & & & & & & & \\
\hline $4 \mathrm{OPD}$ & $.72^{* * *}$ & $.23^{* * *}$ & $.79^{* * * *}$ & --- & & & & & & & & & & & & & \\
\hline $5 \mathrm{SP}$ & $.55^{* * *}$ & $.17^{* * *}$ & $.59^{* * *}$ & $.55^{* * *}$ & --- & & & & & & & & & & & & \\
\hline 6 RK & $.44^{* * * *}$ & $.21^{* * *}$ & $.46^{* * *}$ & $.43^{* * *}$ & $.66^{* * *}$ & --- & & & & & & & & & & & \\
\hline $7 \mathrm{FC}$ & $.55^{* * * *}$ & $.23^{* * *}$ & $.55^{* * * *}$ & $.57^{* * * *}$ & $.81^{* * *}$ & $.63^{* * * *}$ & --- & & & & & & & & & & \\
\hline $8 \mathrm{PW}$ & $.52^{* * *}$ & $.14^{* *}$ & $.53^{* * * *}$ & $.55^{* * *}$ & $.80^{* * *}$ & $.53^{* * *}$ & $.76^{* * *}$ & --- & & & & & & & & & \\
\hline $9 \mathrm{JS}$ & $.38^{* * *}$ & $.26^{* * *}$ & $.35^{* * *}$ & $.33^{* * *}$ & $.32^{* * *}$ & $.21^{* * * *}$ & $.34^{* * * *}$ & $.37^{* * *}$ & --- & & & & & & & & \\
\hline 10 SOCS & $-.37^{* * *}$ & $-.17^{* * * *}$ & $-.40^{* * * *}$ & $-.38^{* * * *}$ & $-.44^{* * * *}$ & $-.33^{* * * *}$ & $-.50^{* * * *}$ & $-.44^{* * * *}$ & $-.34^{* * * *}$ & --- & & & & & & & \\
\hline $11 \mathrm{HA}$ & $.34^{* * *}$ & $.10^{*}$ & $.36^{* * * *}$ & $.33^{* * *}$ & $.51^{* * * *}$ & $.25^{* * *}$ & $.51^{* * *}$ & $.48^{* * *}$ & $.16^{* *}$ & $-.26^{* * *}$ & --- & & & & & & \\
\hline 12 NS & $.12^{*}$ & .06 & $.15^{* *}$ & $.15^{* *}$ & .09 & $.14^{* *}$ & .09 & $.19^{*}$ & .06 & -.03 & $-.20^{* * *}$ & --- & & & & & \\
\hline $13 \mathrm{RD}$ & $-.13^{* *}$ & $-.11^{*}$ & -.05 & -.09 & $-.12^{*}$ & $-.12^{*}$ & $-.23^{* * *}$ & -.08 & -.09 & $.17^{* * *}$ & $-.22^{* * *}$ & $.20^{* * * *}$ & --- & & & & \\
\hline 14 PS & $.14^{* *}$ & $.12^{*}$ & $.12^{*}$ & .05 & $.18^{* * *}$ & $.14^{* *}$ & .07 & .09 & $.15^{* *}$ & -.09 & -.03 & .09 & $.13^{* *}$ & --- & & & \\
\hline $15 \mathrm{SD}$ & $-.41^{* * *}$ & $-.18^{* * * *}$ & $-.48^{* * * *}$ & $-.42^{* * * *}$ & $-.62^{* * *}$ & $-.41^{* * *}$ & $-.60^{* * * *}$ & $-.57^{* * * *}$ & $-.25^{* * *}$ & $.35^{* * *}$ & $-.55^{* * *}$ & $-.24^{* * * *}$ & .08 & $-.31^{* * * *}$ & --- & & \\
\hline $16 \mathrm{CO}$ & $-.26^{* * *}$ & $-.22^{* * *}$ & $-.23^{* * *}$ & $-.23^{* * *}$ & $-.30^{* * * *}$ & $-.31^{* * * *}$ & $-.43^{* * *}$ & $-.24^{* * *}$ & $-.20^{* * * *}$ & $.26^{* * *}$ & $-.33^{* * * *}$ & -.07 & $.43^{* * *}$ & $-.11^{*}$ & $.42^{* * * *}$ & --- & \\
\hline $17 \mathrm{ST}$ & .08 & .07 & .09 & .04 & $.16^{* *}$ & $.16^{* *}$ & .04 & .07 & .08 & -.06 & $-.10^{*}$ & $.24^{* * *}$ & $.16^{* *}$ & $.48^{* * * *}$ & $-.29^{* * *}$ & -.07 & --- \\
\hline
\end{tabular}

TMM, WLQ Time Management; PHD, WLQ Physical Demands; MID, WLQ Mental and Interpersonal Demands; OUD, WLQ Output Demands; SP, CORE-OM Symptomatic Problems; RK, CORE-OM Risk; FC, CORE-OM Functioning; PW, CORE-OM Psychological Well-being; JS, JSQ, Job Strain; SOCS, JSQ, Workplace Social Support; HA, TCI Harm Avoidance; NS, TCI Novelty Seeking; RD, TCI Reward Dependence; PS, TCI Persistence; SD, TCI Self-directedness; CO, TCI, Cooperativeness; ST, TCI Self-transcendence.

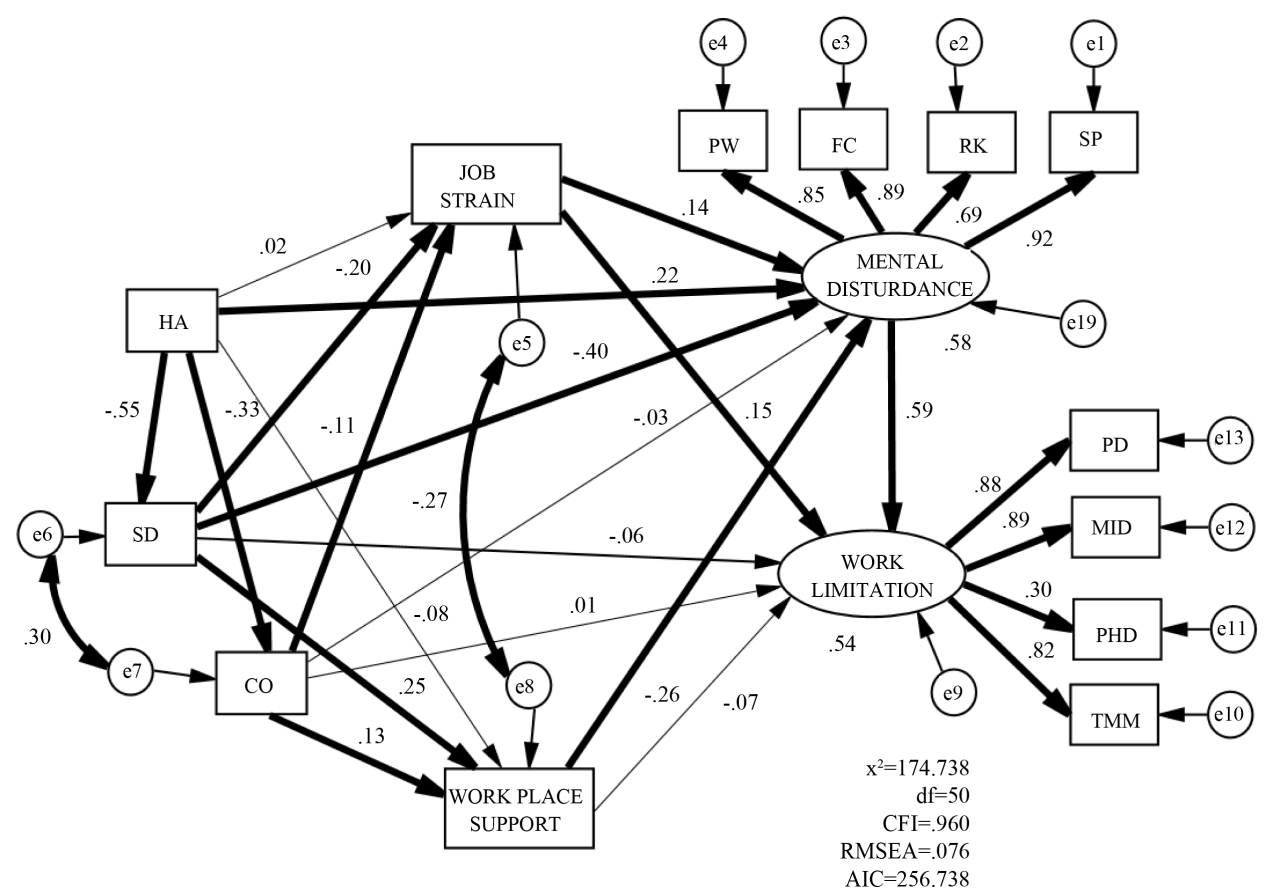

Figure 2. Final path model. TMM, WLQ time management; PHD, WLQ physical demands; MID, WLQ mental and interpersonal demands; OUD, WLQ output demands; SP, CORE-OM symptomatic problems; RK, CORE-OM Risk; FC, COREOM functioning; PW, CORE-OM psychological well-being; JS, JSQ, Job Strain; SOCS, JSQ, workplace social support; HA, TCI Harm Avoidance; NS, TCI novelty seeking; RD, TCI reward dependence; PS, TCI persistence; SD, TCI self-directedness; CO, TCI, Cooperativeness; ST, TCI self-transcendence. 


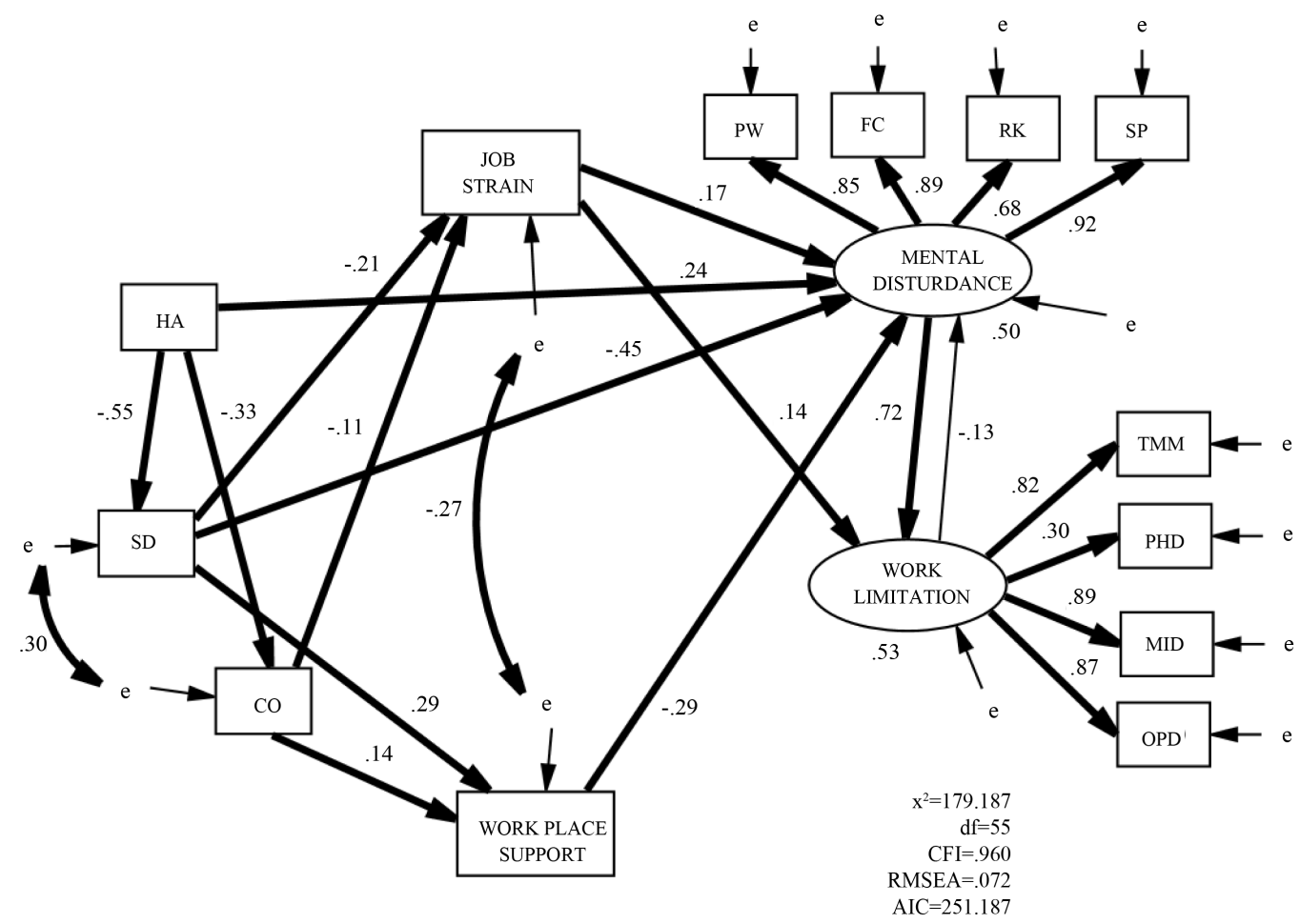

Figure 3. Final non-recursive path model. TMM, WLQ time management; PHD, WLQ physical demands; MID, WLQ mental and interpersonal demands; OUD, WLQ output demands; SP, CORE-OM symptomatic problems; RK, CORE-OM risk; FC, CORE-OM functioning; PW, CORE-OM psychological well-being; JS, JSQ, Job strain; SOCS, JSQ, Workplace social support; HA, TCI harm avoidance; NS, TCI novelty Seeking; RD, TCI reward dependence; PS, TCI persistence; SD, TCI Self-directedness; CO, TCI, Cooperativeness; ST, TCI Self-transcendence.

\section{Discussion}

As predicted from our research hypotheses, presenteeism measured by the WLQ was associated directly with common mental disturbance measured by the CORE-OM and job strain measured by the JSQ. The final SEM model demonstrated that $53 \%$ of the variance of the presenteeism could be explained by these two variables. Because this was a cross-sectional study, we examined the possibility that presenteeism would predict common mental symptoms rather than the other way round (Figure 3). The path from presenteeism toward common mental symptoms was not significant but the path from common mental symptoms toward presenteeism was significant. Thus we presumed that presenteeism was the result of common mental symptoms.

Of clinical and research interest is the lack of direct path from workplace social support towards presenteeism although workplace social support decreased the severity of common mental symptoms directly. Thus job strain and workplace social support, though sharing a substantial variance between each other acted upon presenteeism differentially.

Another unique finding of this study is the attention paid to the effects of temperament traits, Harm Avoidance in particular, and character traits, Self-directedness and Cooperativeness, on job strain, workplace social support, common mental symptoms, and presenteeism. As indicated by many previous investigations, high Ham Avoidance and low Self-directedness were associated directly with common mental symptoms (cited in Introduction). They were also related to mental symptoms via higher job strain and poorer workplace social support. They were never associated directly with presenteeism. Low Cooperativeness, often reported as being linked to common mental symptoms, lost its direct link toward common mental symptoms but indirectly predicted common mental symptoms through higher job strain and poorer workplace social support. To our best knowledge, this is the first report to refer to the mediating effects of job strain and poor workplace social support on the association between low Self-directedness and Cooperativeness and common mental symptoms. People low in Self-directedness and Cooperativeness may be more likely to cope with the stressful job situations with malad- 
justive styles and less likely to create supportive interpersonal relationships with peers. The latter leads to common mental symptoms creating presenteeism at workplace. Harm Avoidance, a temperament trait, though linked to common mental symptoms, had no direct paths toward job strain and poor workplace social support.

The clinical implications of this study in regard occupation mental health are three-fold. First, this study indicated that presenteeism in a IT employee population in Japan was moderately linked to common mental symptoms. More emphasis should be paid to mental health of employees in workplace where presenteeism is an important issue. Second, job strain, though having a direct path toward presenteeism, exerts its effects on presenteeism via common mental symptoms. This is coupled with the negative effects of poor workplace social support. Highly strained work situations are thus at risk of mental disorders as well as presenteeism. Third, the present study highlighted importance of personality and character in particular in understanding the mechanism of presenteeism. When coping with presenteeism at workplace, mental health professionals must carry out careful scrutiny of employees' personality. This may lead to better method of not only approaching mental health problems and presenteeism but also creating effective way to prevent such mental health problems.

Limitations of this study include many issues. First, this is a cross-sectional study. We should exercise care when discussing causality. Prospective follow-up studies of employees are essential next steps in the future. However, use of SEM in this study made it possible to speculate such causality. Particularly, a non-recursive model seems to have made such perspective study promising that common mental symptoms are not the result but the mediators of workplace presenteeism. Second, the attrition rate was about $80 \%$. We sent a reminder mail to the eligible employees. However, this did not recruit much more responders. Furthermore we heavily relied on employees' self-report for assessing all the variables. Although web-based investigation was the only option we obtained within a limited resources, replication of the results of this study should conducted in interviewbased studies. In addition, we were unable to make psychiatric diagnosis in workplace participants although the CORE-OM is a reliable and valid measure of general severity of psychological maladjustment. Use of diagnostic structured interview may be a strong method that should be used in future studies.

\section{Conclusion}

Our first hypothesis "presenteeism was predicted by job strain as well as lack of workplace social support" was partly supported: Presenteeism was predicted by job strain but indirectly by lack of workplace social support. Our second hypothesis "this effect is mediated by common mental symptoms" was supported. The third hypothesis "high Harm Avoidance and low Self-directedness and Cooperativeness predict presenteeism and common mental symptoms directly” was only partially supported: High Harm Avoidance and low Self-directedness predicted only common mental symptoms that fully mediated the effects on presenteeism. The effect of Cooperativeness on common mental symptoms was mediated via high job strain and pure workplace social support. The last hypothesis "The effects High Harm Avoidance and low Self-directedness and Cooperativeness on presenteeism and common mental symptoms are mediated by job strain as well as lack of workplace social support” was also partly supported: The effects of low Self-directedness and Cooperativeness but not that of high Harm Avoidance were mediated by job strain and poor workplace support.

Taking into consideration the methodological drawbacks, this study suggested that workplace presenteeism in Japanese IT companies could be explained to certain extent by common mental symptoms and job strain and that common mental symptoms mediated the effects of job strain and poor workplace social support as well as high Harm Avoidance and low Self-directedness and Cooperativeness upon presenteeism.

\section{References}

Alonso, P., Menchón, J. M., Jiménez, S., Segalàs, J., Mataix-Cols, D., Jaurrieta, N., \& Pujol, J. (2008). Personality Dimensions in Obsessive-Compulsive Disorder: Relation to Clinical Variables. Psychiatry Research, 157, 159-168. http://dx.doi.org/10.1016/j.psychres.2006.06.003

Álvarez-Moya, E. M., Jiménez-Murcia, S., Granero, R., Vallejo, J., Krug, I., Bulik, C. M., \& Fernández-Aranda, F. (2007). Comparison of Personality Risk Factors in Bulimia Nervosa and Pathological Gambling. Comprehensive Psychiatry, 48, 452-457. http://dx.doi.org/10.1016/j.comppsych.2007.03.008

Anderson, K., \& Andrews, G. (2006). Common Mental Disorders in the Workplace: Recent Findings from Descriptive and Social Epidemiology. Canadian Journal of Psychiatry, 51, 63-75.

Bejerot, S., Schlette, P., Ekselius, L., Adolfsson, R., \& von Knorring, L. (1998). Personality Disorders and Relationship to Personality Dimensions Measured by the Temperament and Character Inventory in Patients with Obsessive-Compulsive 
Disorder. Acta Psychiatrica Scandinavica, 98, 243-249. http://dx.doi.org/10.1111/j.1600-0447.1998.tb10075.x

Bergeman, C. S., Plomin, R., Pedersen, N. L., McClea, G. E., \&Nesselroade, J. R. (1990). Genetic and Environmental Influences on Social Support: The Swedish Adoption/Twin Study of Aging. Journal of Gerontology: Psychological Sciences, 45, 101-106. http://dx.doi.org/10.1093/geronj/45.3.P101

Bolger, N., \& Eckenrode, J. (1991). Social Relationships, Personality, and Anxiety during A Major Stressful Event. Journal of Personality and Social Psychology, 61, 440-449. http://dx.doi.org/10.1037/0022-3514.61.3.440

Brown, H. E., Gilson, N. D., Burton, N. W., \& Brown, W. J. (2011). Does Physical Activity Impact on Presenteeiasm and Other Indicators of Workplace Well-Being? Sports Medicine, 41, 249-262.

http://dx.doi.org/10.2165/11539180-000000000-00000

Burton, W. N., Pransky, G., Conti, D. J., Chen, C.-Y., \& Edington, D. W. (2004). The Association of Medical Conditions and Presenteeism. Journal of Occupational Medicine, 46, s38-s45. http://dx.doi.org/10.1097/01.jom.0000126687.49652.44

Cassin, S. E., \& von Ranson, K. M. (2005). Personality and Eating Disorders: A Decade in Review. Clinical Psychology Review, 25, 895-916. http://dx.doi.org/10.1016/j.cpr.2005.04.012

Celikel, F. C., Kose, S., Cumurcu, B. E., Erkorkmaz, U., Sayar, K., Borckardt, J. J., \& Cloninger, C. R. (2009). Cloninger’s Temperament and Character Dimensions of Personality in Patients with Major Depressive Disorder. Comprehensive Psychiatry, 50, 556-5621. http://dx.doi.org/10.1016/j.comppsych.2008.11.012

Cho, S. C., Jung, S. W., Kim, B. N., Hwang, J. W., Shin, M. S., Kim, J. W. et al. (2009). Temperament and Character among Korean Children and Adolescents with Anxiety Disorders. European Child and Adolescent Psychiatry, 18, 60-64. http://dx.doi.org/10.1007/s00787-008-0699-3

Cloninger, C. R. (1999). The Temperament and Character Inventory-Revised. St. Louis., MI: Centre for Psychobiology of Personality, Washington University.

Cloninger, C. R., Svrakic, D. M., \& Przybeck, T. R. (1993). A Psychobiological Model of Temperament and Character. Archives of General Psychiatry, 50, 975-990. http://dx.doi.org/10.1001/archpsyc.1993.01820240059008

Cloninger, C. R., Przybeck, T. R., Svrakic, D. M., \& Wetzel, R. D. (1994). The Temperament and Character Inventory (TCI): A Guide to Its Development and Use. St. Louis., MI: Centre for Psychobiology of Personality, Washington University.

Cooper, C., \& Dewe, P. (2008). Well-Being: Absenteeism, Presenteeism, Coasts and Challenges. Occupational Medicine, 58, 522-524. http://dx.doi.org/10.1093/occmed/kqn124

Daley, S. E., Hammen, C., Davila, J., \& Burge, D. (1998). Axis II Symptomatology, Depression, and Life Stress during the Transition from Adolescence to Adulthood. Journal of Consulting and Clinical Psychology, 66, 595-603. http://dx.doi.org/10.1037/0022-006X.66.4.595

De Lange, A. H., Taris, T. W., Kompier, M. A., Houtman, I. L. D., \& Bongers, P. M. (2003). “The Very Best of the Millennium”: Longitudinal Research and the Demand-Control (Support) Model. Journal of Occupational Health Psychology, 8 , 282-305. http://dx.doi.org/10.1037/1076-8998.8.4.282

Engström, C., Brändström, S., Sigvardsson, S., Cloninger, C. R., \& Nylander, P. O. (2004). Bipolar Disorder. I. Temperament and Character. Journal of Affective Disorders, 82, 131-134. http://dx.doi.org/10.1016/j.jad.2003.09.004

Evans, C., Connell, J., Barkham, M., Margison, F., McGrath, G., Mellor-Clark, J., \& Audin, K. (2002). Towards a Standardized Brief Outcome Measure: Psychometric Properties and Utility of the CORE-OM (Clinical Outcomes in Routine Evaluation-Outcome Measure). British Journal of Psychiatry, 180, 51-60. http://dx.doi.org/10.1192/bjp.180.1.51

Evans, C., Mellor-Clark, J., Margison, F., Barkham, M., Audin, K., Connell, J., \& McGrath, G. (2000). CORE: Clinical Outcomes in Routine Evaluation. Journal of Mental Health Nursing, 9, 247-255. http://dx.doi.org/10.1080/713680250

Evans, L., Akiskal, H. S., Keck Jr., P. E., McElroy, S. L., Sadovnick, A. D., Remick, R. A., \& Kelsoe, J. R. (2005). Familiarity of Temperament in Bipolar Disorder: Support for a Genetic Spectrum. Journal of Affective Disorders, 85, 153-168. http://dx.doi.org/10.1016/j.jad.2003.10.015

Farmer, A., Harris, T., Redman, K., Sadler, S., Mahmood, A., \& McGuffin, P. (2000). Cardiff Depression Study: A Sib-Pair Study of Life Events and Familiarities in Major Depression. British Journal of Psychiatry, 176, 150-155. http://dx.doi.org/10.1192/bjp.176.2.150

Farmer, A., Mahmood, A., Redman, K., Harris, T., Sadler, S., \& McGuffin, P. (2003). A Sib-Pair Study of the Temperament and Character Inventory Scales in Major Depression. Archives of General Psychiatry, 60, 490-496. http://dx.doi.org/10.1001/archpsyc.60.5.490

Farmer, R. F., \& Seeley, J. R. (2009). Temperament and Character Predictors of Depressed Mood over a 4-Year Interval. Depression and Anxiety, 26, 371-381. http://dx.doi.org/10.1002/da.20459

Finch, J. F., \& Graziano, W. G. (2001). Predicting Depression from Temperament, Personality, and Patterns of Social Rela- 
tions. Journal of Personality, 69, 27-55. http://dx.doi.org/10.1111/1467-6494.00135

Ghazinour, M., Richter, J., \& Eisemann, M. (2003). Personality Related to Coping and Social Support among Iranian Refugees in Sweden. Journal of Nervous and Mental Disease, 191, 595-603. http://dx.doi.org/10.1097/01.nmd.0000087186.03513.38

Goetzel, R. Z., Long, S. R., Ozminkowski, R. J., Hawkins, K., Wang, S., \& Lynch, W. (2004). Health, Absence, Disability, and Presenteeism Cost Estimates of Certain Physical and Mental Health Conditions Affecting US Employers. Journal of Occupational and Environmental Medicine, 46, 398-412. http://dx.doi.org/10.1097/01.jom.0000121151.40413.bd

Goncalves, D. M., \& Cloninger, C. R. (2010). Validation and Normative Studies of the Brazilian Portuguese and American Versions of the Temperament and Character Inventory-Revised (TCI-R). Journal of Affective Disorders, 124, 126-133. http://dx.doi.org/10.1016/j.jad.2009.11.007

Hansenne, M., Pitchot, W., Moreno, A. G., Machurot, P. Y., \& Ansseau, M. (1998). The Tridimensional Personality Questionnaire (TPQ) and Depression. European Psychiatry, 13, 101-103. http://dx.doi.org/10.1016/S0924-9338(98)80026-6

Hansenne, M., Reggers, J., Pinto, E., Kjiri, K., Ajamier, A., \& Ansseau, M. (1999). Temperament and Character Inventory (TCI) and Depression. Journal of Psychiatric Research, 33, 31-36. http://dx.doi.org/10.1016/S0022-3956(98)00036-3

Hazel, N. A., Hammen, C., Brennan, P. A., \& Najman, J. (2008). Early Childhood Adversity and Adolescent Depression: The Mediating Role of Continued Stress. Psychological Medicine, 38, 518-589. http://dx.doi.org/10.1017/S0033291708002857

Ida, H., Nakagawa, K., Miura, M., Ishikawa, K., \& Yakura, N. (2012). Development of the Work Limitation Questionnaire Japanese Version (WLQ-J): Fundamental Examination of the Reliability and Validity of the WLQ-J. Sangyo Eiseigaku Zasshi, 54, 101-107. (In Japanese) http://dx.doi.org/10.1539/sangyoeisei.b11011

Janowsky, D. S., Morter, S., Hong, L., \& Howe, L. (1999). Myers Biggs Type Indicator and Tridimensional Personality Questionnaire Differences between Bipolar Patients and Unipolar Depressed Patients. Bipolar Disorders, 2, 98-108. http://dx.doi.org/10.1034/j.1399-5618.1999.010207.x

Jylhä, P., \& Isometsä, E. (2006). Temperament, Character and Symptoms of Anxiety and Depression in the General Population. European Psychiatry, 21, 389-395. http://dx.doi.org/10.1016/j.eurpsy.2005.09.003

Jylhä, P., Mantere, O., Melartin, T., Suominenm, K., Vuorilehto, M., Arvilommi, P. et al. (2011). Differences in Temperament and Character Dimensions in Patients with Bipolar I and II or Major Depressive Disorder and General Population Subjects. Psychological Medicine, 41, 1579-1591. http://dx.doi.org/10.1017/S0033291710002606

Karasek, R. (1979). Job Demands, Job Decision Latitude and Mental Strain: Implications for Job Redesign. Administrative Science Quarterly, 24, 285-308. http://dx.doi.org/10.2307/2392498

Kendler, K. S., Karkowski, L. M., \& Prescott, C. A. (1999). The Assessment of Dependence in the Study of Stressful Life Events: Validation Using a Twin Design. Psychological Medicine, 29, 1455-1460. http://dx.doi.org/10.1017/S0033291798008198

Kim, S. J., Kang, J. I., \& Kim, C. H. (2009). Temperament and Character in Subjects with Obsessive-Compulsive Disorder. Comprehensive Psychiatry, 50, 567-572.

Klein, R. B. (2005). Principles and Practice of Structural Equation Modeling (2nd ed.). New York: Guilford.

Koenen, K. C., Moffitt, T. E., Poulton, R., Martin, J., \& Caspi, A. (2006). Early Childhood Factors Associated with the Development of Post-Traumatic Stress Disorder: Results from a Longitudinal Birth Cohort. Psychological Medicine, 37, 181192.

Kessler, R. C., Kendler, K. S., Heath, A., Neale, M. C., \& Eaves, L. J. (1992). Social Support, Depressed Mood, and Adjustment to Stress: A Genetic Epidemiologic Investigation. Journal of Personality and Social Psychology, 62, 257-272. http://dx.doi.org/10.1037/0022-3514.62.2.257

Kusunoki, K., Sato, T., Taga, C., Yoshida, T., Komori, K., Narita, T. et al. (2000). Low Novelty-Seeking Differentiates Obsessive-Compulsive Disorder from Major Depression. Acta Psychiatrica Scandinavica, 101, 403-405. http://dx.doi.org/10.1034/j.1600-0447.2000.101005403.x

Lerner, D., Adler, D. A., Chang, H., Berndt, E. R., Irish, J. T., Lapitsky, L. et al. (2004). The Clinical and Occupational Correlates of Work Productivity Loss among Employed Patients with Depression. Journal of Occupational and Environmental Medicine, 46, s46-s55. http://dx.doi.org/10.1097/01.jom.0000126684.82825.0a

Lerner, D., Adler, D. A., Chang, H., Lapitsky, L., Hood, M. Y., Perissinotto, C. et al. (2004). Unemployment, Job Retention, and Productivity Loss among Employees with Depression. Psychiatric Services, 55, 1371-1378. http://dx.doi.org/10.1176/appi.ps.55.12.1371

Lerner, D., Amick III, B. C., Lee, J. C., Rooney, T., Rogers, W. H., Chang, H., \& Berndt, E. R. (2003). Relationship of Employee-Reported Work Limitations to Work Productivity. Medical Care, 41, 649-659.

http://dx.doi.org/10.1097/01.MLR.0000062551.76504.A9 
Lerner, D., Amick III, B. C., Rogers, W. H., Malspeis, S., \& Bungay, K. (2001). The Work Limitation Questionnaire: A Self-Administered Instrument for Assessing On-the-Job Work Disability. Medical Care, 39, 72-85. http://dx.doi.org/10.1097/00005650-200101000-00009

Lerner, D., \& Henke, R. M. (2008). What Does Research Tell Us about Depression, Job Performance, and Work Productivity? Journal of Occupational and Environmental Medicine, 50, 401-410. http://dx.doi.org/10.1097/JOM.0b013e31816bae50

Lerner, D., Reed, J. I., Massarotti, E., Wester, L. M., \& Burke, T. A. (2002). The Work Limitation Questionnaire’s Validity and Reliability among Patients with Osteoarthritis. Journal of Clinical Epidemiology, 55, 197-208. http://dx.doi.org/10.1016/S0895-4356(01)00424-3

Loftus, S. T., Garno, J. L., Jaeger, J., \& Malhotra, A. K. (2008). Temperament and Character Dimensions in Bipolar I Disorder: A Comparison to Healthy Controls. Journal of Psychiatric Research, 42, 1131-1136. http://dx.doi.org/10.1016/j.jpsychires.2007.11.005

Maciejewski, P. K., Prigerson, H. G., \& Mazure, C. M. (2000). Self-Efficacy as a Mediator between Stressful Life Events and Depressive Symptoms: Differences Based on History of Prior Depression. British Journal of Psychiatry, 176, 373378. http://dx.doi.org/10.1192/bjp.176.4.373

Marchesi, C., De Panfilis, C., Cantoni, A., Giannelli, M. R., \& Maggini, C. (2008). Effect of Pharmacological Treatment on Temperament and Character in Panic Disorder. Psychiatric Research, 158, 147-154. http://dx.doi.org/10.1016/j.psychres.2006.08.009

Matsudaira, T., \& Kitamura, T. (2006). Personality Traits as Risk Factors of Depression and Anxiety among Japanese Students. Journal of Clinical Psychology, 62, 97-109. http://dx.doi.org/10.1002/jclp.20215

Middledorp, C. M., Cath, D. C., Beem, A. L., Willemsen, G., \& Boomsma, D. I. (2008). Life Events, Anxious Depression and Personality: A Prospective and Genetic Study. Psychological Medicine, 38, 1557-1565.

http://dx.doi.org/10.1017/S0033291708002985

Minaya, O., \& Fresán, A. (2009). Anxiety Disorders Comorbidity in First-Episode Depressed Patients: Personality Differences Based on the Temperament and Character Inventory. Personality and Individual Differences, 47, 522-526. http://dx.doi.org/10.1016/j.paid.2009.05.006

Mörtberg, E., Bejerot, S., \& Wistedt, A. Å. (2007). Temperament and Character Dimensions in Patients with Social Phobia: Patterns of Change Following Treatments? Psychiatry Research, 152, 81-90.

http://dx.doi.org/10.1016/j.psychres.2006.10.003

Nery, F. G., Hatch, J. P., Glahn, D. C., Nicoletti, M. A., Monkul, E. S., Najt, P. et al. (2008). Temperament and Character traits in Patients with Bipolar Disorder and Associations with Comorbid Alcoholism or Anxiety Disorders. Journal of Psychiatric Research, 42, 569-577. http://dx.doi.org/10.1016/j.jpsychires.2007.06.004

Pallanti, S. (2007). Social Anxiety Disorder and Temperament: Excitatory and Inhibitory Mechanisms on Primary Motor Cortex in Patients and Healthy Controls. European Psychiatry, 22, S284-S284. http://dx.doi.org/10.1016/j.eurpsy.2007.01.961

Park, K. O., Wilson, M. G., \& Lee, M. S. (2004). Effects of Social Support at Work on Depression and Organizational Productivity. American Journal of Health Behavior, 28, 444-455. http://dx.doi.org/10.5993/AJHB.28.5.7

Ruchkin, V. V., Schwab-Stone, M., Koposov, R. Vermeiren, R., \& Steiner, H. (2002). Violence Exposure, Posttraumatic Stress, and Personality in Juvenile Delinquents. Journal of the American Academy of Child and Adolescent Psychiatry, 41, 322-329. http://dx.doi.org/10.1097/00004583-200203000-00012

Sato, T., Narita, T., Hirano, S., Kusunoki, K., Sakado, K., \& Uehara, T. (2001). Is Interpersonal Sensitivity Specific to Non-melancholic Depression? Journal of Affective Disorders, 64, 133-144. http://dx.doi.org/10.1016/S0165-0327(00)00222-6

Sayın, A., Kuruoğlu, A. Ç., Güeç, M. Y., \& Aslan, S. (2007). Relation of Temperament and Character Properties with Clinical Presentation of Bipolar Disorder. Comprehensive Psychiatry, 48, 448-451. http://dx.doi.org/10.1016/j.comppsych.2007.04.004

Steptoe, A., Cropley, M., \& Joekes, K. (1999). Job Strain, Blood Pressure and Response to Uncontrollable Stress. Journal of Hypertension, 17, 193-200. http://dx.doi.org/10.1097/00004872-199917020-00003

Takagishi, Y., Sakata, M., \& Kitamura, T. (2011). Effects of Self-Esteem on State and Trait Components of Interpersonal Dependency and Depression in the Workplace. Journal of Clinical Psychology, 67, 918-926. http://dx.doi.org/10.1002/jclp.20815

Tanaka, E., Kijima, N., \& Kitamura, T. (1997). Correlations between the Temperament and Character Inventory and the Self-Rating Depression Scale among Japanese Students. Psychological Reports, 80, 251-254. http://dx.doi.org/10.2466/pr0.1997.80.1.251

Tillman, R., Geller, B., Craney, J. L., Bolhofner, K., Williams, M., Zimerman, B. et al. (2003). Temperament and Character 
Factors in a Prepubertal and Early Adolescent Bipolar Disorder Phenotype Compared to Attention Deficit Hyperactive and Normal Controls. Journal of Child and Adolescent Psychopharmacology, 13, 531-543.

http://dx.doi.org/10.1089/104454603322724922

Tse, W. S., \& Bond, A. J. (2003). Consequences of Displaying Abnormal Social Behaviour: Avoidance and Reduction of Social Reinforcement. Journal of Affective Disorders, 75, 49-58. http://dx.doi.org/10.1016/S0165-0327(02)00036-8

Uji, M., Sakamoto, A., Adachi, K., \& Kitamura, T. (2012). Psychometric Properties of the Japanese Version of the Clinical Outcomes in Routine Evaluation-Outcome Measure. Comprehensive Psychiatry, 53, 600-608. http://dx.doi.org/10.1016/j.comppsych.2011.09.006

Wachleski, C., Salum, G. A., Blaya, C., Kipper, L., Paludo, A., Salgado, A. P., \& Manfro, G. G. (2008). Harm Avoidance and Self-Directedness as Essential Features of Panic Disorder Patients. Comprehensive Psychiatry, 49, 476-481. http://dx.doi.org/10.1016/j.comppsych.2008.03.003

Yoon, S. J., Jun, C. S., An, H. Y., Kang, H. R., \& Jun, T. Y. (2009). Patterns of Temperament and Character in Patients with Posttraumatic Stress Disorder and Their Association with Symptom Severity. Comprehensive Psychiatry, 50, $226-231$. http://dx.doi.org/10.1016/j.comppsych.2008.08.003 